\title{
Pathologic Findings in a Case of Pseudolipoma of the Liver, and its Differential Diagnosis
}

\section{ABSTRACT}

The name pseudolipoma of Glisson capsule is used interchangeably with another commonly used term, hepatic pseudolipoma, the prevalence of which, as mentioned by Karhunen is $0.2 \%$. The mean age of occurrence is 67 years. These are fatty masses mainly found on the diaphragmatic aspect of Glisson's capsule. They are more common in men than in women, and are usually asymptomatic. So, they are only seen at necropsy, or as an incidental finding on radiology or intraoperatively. Macroscopically, these innocent lesions may mimic metastatic carcinoma, and microscopically they must be distinguished from true hepatic lipomas, parasites (hydatid cysts) or solitary sub capsular necrotic nodule.

We report a case of idiopathic pyloric stenosis, with an incidental finding of a calcified lesion in liver on CT scan, which was differentially diagnosed as calcified hydatid cyst or calcified old abscess by the radiologist. On microscopy, the lesion was diagnosed as pseudolipoma of the Glisson's capsule.

Keywords: Incidental finding, Lipoma, Solitary necrotic nodule of liver

\section{CASE REPORT}

A 46 years old male presented in Gastroenterology Department, with the chief complaints of off and on vomiting, loss of appetite and generalized body aches, for the past one and a half month. There was no history of previous abdominal surgery. CT-scan showed a circumferential thickening of antro-pyloric region of stomach, along with mild splenomegaly. It also showed a calcified lesion in liver, and the possibilities of calcified hydatid cyst, or calcified old abscess were suggested by the radiologist. Endoscopy was performed and balloon dilation was done. But since the symptoms were not relieved, finally open laparotomy was done, and a segment of the stomach, including the thickened pylorus was removed. Intraoperatively, the surgeon found the nodule mentioned on CT, protruding from the surface of the right lobe of the liver, measuring around $2 \times 2 \mathrm{~cm}$. It was removed and sent for histopathological examination. The nodule was round to oval, firm and measured $2 \times 1.2 \times 0.5 \mathrm{~cm}$ in size. The cut surface showed yellow to white homogenous areas [Table/Fig-1].

Routine histopathological processing was done and sections were prepared, which showed a thick hyalinized capsule underneath which were seen clusters of polygonal cells lacking nuclei and focally filled with basophilic material.
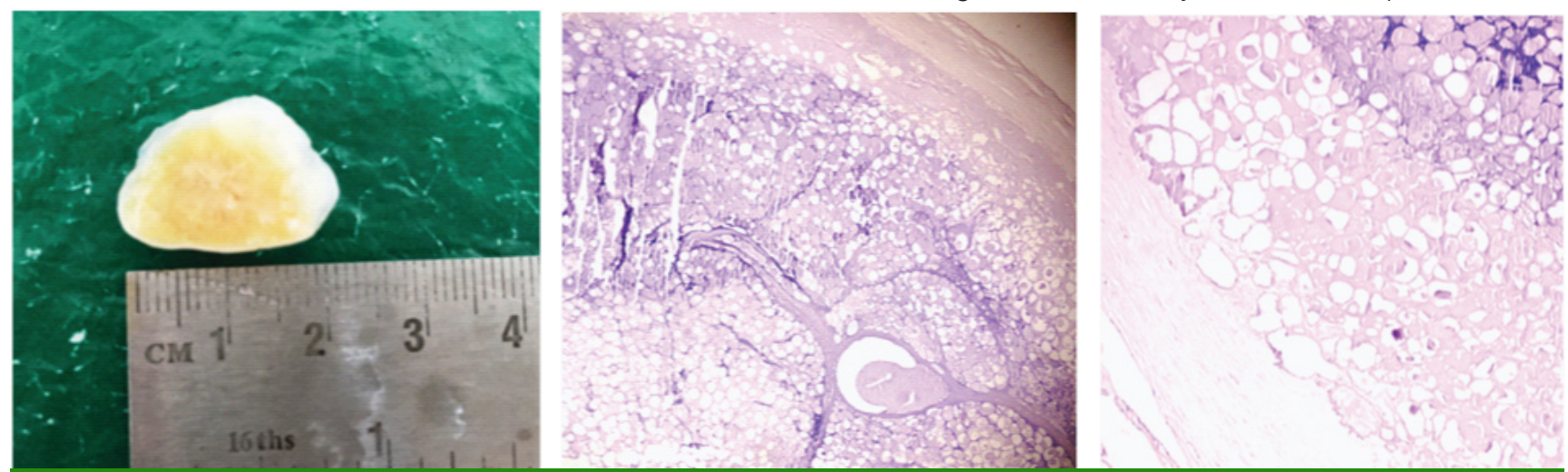

[Table/Fig-1]: Gross examination showed an oval, whitish -yellow, smooth surfaced, firm nodule measuring ar ound $2 \times 1.5 \mathrm{~cm}$, which showed a yellowish center on cut section. [Table/Fig-2]: Section showed an encapsulated nodule showing shadowy outlines of necrotic adipocytes, lacking nuclei. (H\&E x50). [Table/Fig-3]: Low power showed necrotic adipocytes, having foci of dystrophic calcification. (H\&E x 100). 
After a review of literature, a diagnosis of pseudolipoma of the Glisson's capsule was made. Sections from the stomach showed idiopathic hypertrophic pyloric stenosis [Table/Fig-2,3]. The patient was discharged in a stable condition. He is on regular follow-up.

\section{DISCUSSION}

Pseudolipoma is defined as an encapsulated lesion that contains degenerated fat and is enveloped by the liver capsule [1]. This entity was described by Rolleston in 1891, who postulated that it arises from a detached piece of epiploic appendix that undergoes degeneration and later calcification, and becomes lodged between the diaphragm and the liver [2]. It is also thought that it may be caused by traumatic inclusion of fat within the liver capsule during surgery, or by transcutaneous liver biopsy. [3]

A previous history of abdominal surgery is present in many patients [4]. On CT, it appears as a well-circumscribed nodule on the liver surface with a center of fat or soft-tissue attenuation [1]. The size of the reported pseudolipomas ranges from $0.4-2.0 \mathrm{~cm}$ [5], corresponding with our finding. It does not require any treatment, because it does not produce any symptoms [5].

The pseudolipoma can mimic a hepatic lipoma from which it can be distinguished by the presence of fibrous encapsulation and well defined margins. A lipoma, on the other hand, has irregular margins and is not encapsulated [6]. On microscopic examination, a true lipoma contains lobules of viable mature adipocytes, unlike ghost cells containing basophilic material in a pseudo lipoma.

Because of its subcapsular location, pseudolipoma protrudes from the surface of the liver, and can be confused grossly with metastatic nodules, like those from cancers of the prostate and large intestine [7].

The other differential diagnosis of this uncommon entity includes a solitary necrotic nodule of the liver. This entity is a subcapsular nodule having a necrotic core surrounded by collagenized fibrous tissue. These lesions are usually asymptomatic like a pseudolipoma, and they are detected incidentally during preoperative evaluation for some other cause, or during surgery [8]. FNAC yields necrotic material only, and the only way of making a certain diagnosis is histopthology. The pathogenesis of the solitary necrotic nodule is still not clear. In their study, Shepherd et al., suggested that these are sequelae of trauma or infection [9]. Sunderasan et al., [10], showed the presence of the feeding vessels within the nodule. They also described reticulin fibres within the nodule, and suggested the diagnosis of a sclerosing hemangioma. Parasitic infections including hydatid cyst are likely to be the cause in certain cases [11].

\section{CONCLUSION}

Pseudolipomas are benign, harmless lesions, and are usually incidental findings on radiology, during surgery, or autopsy. They must be included in the list of differential diagnosis of solitary nodular lesions of the liver, and the pathologist must be aware of their histopathological findings to be able to differentiate them from other mimics.

\section{REFERENCES}

[1] Quinn AM and Guzman-Hartman G. Pseudolipoma of glisson capsule. Arch Pathol Lab Med. 2003; 127:503-04.

[2] Rolleston HD. Lipoma of liver (appendix epiploica). Pathol Soc Lond Trans.1891; 42:160-61.

[3] Fievez M, Courtoy P Les pseudo-lipomes de la capsule de Glisson. Gastroenterol Clin Biol. 1978; 2:273-77.

[4] Sasaki M, Harada K, Nakanuma Y, Watanabe K. Pseudolipoma of Glisson's capsule. Report of 6 cases and review of literature. J Clin Gastroenterol. 1994; 19(1): 75-78.

[5] Karhunen PJ. Hepatic pseudolipoma. J Clin Pathol. 1985; 38:877-79.

[6] Pounder DJ. Hepatic pseudolipoma. Pathology. 1983; 15:83-84.

[7] Benbow EW, Reid H. Pseudolipoma of Glisson's capsule simulating metastatic tumour. Journal of Clinical Pathol. 1986; 39(3):345-46.

[8] Patti R, Cabibi D, Sparacello M, Di Vita G, Montalgo G. Solitary necrotic nodule of the liver; different pathological findings express a different histogenesis. Case Rep Gastroenterol. 2008; 2:149-54.

[9] Shepherd NA, Lee G. Solitary necrotic nodule of the liver simulating hepatic metastasis. J Clin Pathol. 1983; 36:1181-83.

[10] Sundaresan M, Lyons B, Akosa AB. 'Solitary' necrotic nodules of the liver: an aetiology reaffirmed. Gut. 1991; 32:1378-80.

[11] Deniz K, Coban G. Solitary necrotic nodule of the liver; always benign? J Gastrointest Surg. 2010; 14:536-40.

\section{AUTHOR(S): \\ 1. Dr. Monika Bansal \\ 2. Dr. Puneet Kaur \\ 3. Dr. Anureet Kaur}

\section{PARTICULARS OF CONTRIBUTORS:}

1. Associate Professor, Department of Pathology, Gian Sagar Medical College and Hospital, Banur, Patiala, India.

2. Assistant Professor, Department of Pathology, Gian Sagar Medical College and Hospital, Banur, Patiala, India.
3. Professor, Department of Pathology, Gian Sagar Medical College and Hospital, Banur, Patiala, India.

\section{NAME, ADDRESS, E-MAIL ID OF THE} CORRESPONDING AUTHOR:

Dr. Monika Bansal,

302, Marigold Tower, Mayfair, Apartment,

Sector 70, Mohali, Punjab, India.

E-mail: monika_bansal78@yahoo.com

FINANCIAL OR OTHER COMPETING INTERESTS:

None

Date of Publishing: Apr 01, 2016 